Biosynthesis of the cyclotide Kalata B1 using protein splicing tools

R. Kimura, K. Krishnan, J. A. Camarero

July 29, 2005

19th American Peptide Symposium

San Diego, CA, United States

June 18, 2005 through June 23, 2005 
This document was prepared as an account of work sponsored by an agency of the United States Government. Neither the United States Government nor the University of California nor any of their employees, makes any warranty, express or implied, or assumes any legal liability or responsibility for the accuracy, completeness, or usefulness of any information, apparatus, product, or process disclosed, or represents that its use would not infringe privately owned rights. Reference herein to any specific commercial product, process, or service by trade name, trademark, manufacturer, or otherwise, does not necessarily constitute or imply its endorsement, recommendation, or favoring by the United States Government or the University of California. The views and opinions of authors expressed herein do not necessarily state or reflect those of the United States Government or the University of California, and shall not be used for advertising or product endorsement purposes. 


\title{
Biosynthesis of the cyclotide Kalata B1 using protein splicing tools
}

\author{
Richard Kimura $^{1}$, Krish Krishnan ${ }^{2}$ and Julio A. Camarero ${ }^{1}$ \\ ${ }^{I}$ Chemical Biology and Nuclear Sciences Division; ${ }^{2}$ Biosciences Directorate, Lawrence \\ Livermore National Laboratory, University of California, Livermore, CA 94550, USA
}

\section{Introduction}

Cyclotides are a new emerging family of large cyclic polypeptides $(\approx 30$ residues long) that share a disulfide-stabilized core ( 3 disulfide bonds) with an unusual knotted structure (Fig. 1A) [1]. Cyclotides contrast with other circular poylpeptides in that they have a highly defined three-dimensional structure, and despite their small size, can be considered as miniproteins. Their unique circular backbone topology and knotted arrangement of 3 disulfide bonds makes them exceptionally stable to thermal and enzymatic degradation. Furthermore, their well defined structures have been also associated with a range of biological activities, including uterotonic activity, inhibition of neurotension binding, hemolytic, anti-HIV, insecticidal as well as trypsin inhibitory activity. Altogether, these characteristics make cyclotides ideal candidates to be used as molecular scaffolds for the development of stable peptide drugs [2]. Access to biosynthetic cyclotides using recombinant DNA expression techniques would offer the exciting possibility of producing large combinatorial libraries of highly stable miniproteins using the tools of molecular biology. This would allow the generation of cell-based combinatorial libraries that could be screened inside living cells for their ability to regulate cellular processes. In the present work we describe for the first time the biosynthesis of the cyclotide Kalata B1 in E. coli.

\section{Results and Discussion}

Our approach is based on the use of an intramolecular version of the native chemical ligation combined with the use of a modified protein splicing unit [3]. In order to accomplish the cyclization of Kalata B1, the different linear precursors tested in this work (Fig. 1B) were fused at the N-terminus with a Met residue, and at the Cterminus with an VMA engineered intein (available in the pTXB expression vectors family from New England Biolabs). The Met residue was efficiently removed in vivo in $E$. coli by an endogenous Met amino peptidase. This in vivo proteolytic event unmasked the required N-terminal Cys. After affinity purification of the corresponding N-terminal Cys Kalata-Intein fusion protein, the cyclization was triggered by additon of 5\% EtSH (Fig. 1C). Among the different linear precursors that were tested, $\mathrm{KC} 3$ and $\mathrm{KC} 4$ gave the best cyclization yields. The different linear precursors showed also different propensities for in vivo cleavage of the corresponding Kalata-Intein fusion constructs. Thus, meanwhile the $\mathrm{KC} 4$ linear precursor gave only $30 \%$ in vivo cleavage the KC6 precursor was almost completely cleaved in vivo $(>90 \%)$. The resulting reduced circular Kalata B1 was oxidatively folded at $\mathrm{pH} 8.0$ in the presence of reduced gluthathione (GSH) and ${ }^{\mathrm{i}} \mathrm{Pr}-\mathrm{OH}$ (Fig. 1D). The folded recombinant Kalata B1 was characterized by ES-MS, HPLC and 2D-NMR, and it was shown to be identical to the natural product. Encouraged by this result we decided to explore the possibility of carrying out the cyclization and folding in a single-pot reaction. This was accomplished by treating the purified KC4intein construct with different amounts and ratios of reduced and oxidized 
glutathione (GSH and GSSG). The best cleavage/cyclization of the KC4-intein precursor was accomplished using $100 \mathrm{mM}$ of GSH at $\mathrm{pH}$ 7.2, under these conditions the cleavage of the linear $\mathrm{KC} 4$-intein precursor was almost quantitative in less than $18 \mathrm{~h}$. Optimal conditions for the oxidative folding of reduced Kalata B1 were obtained using a buffer containing a GSH:GSSG ratio of $4: 1$ at $\mathrm{pH} 8.0$ in $50 \%$ isopropanol. Hence, the purified KC4-intein linear precursor was treated first with $100 \mathrm{mM}$ GSH at $\mathrm{pH} 7.2$ overnight, then the crude reaction was complemented with isopropanol (50\%) and $12 \mathrm{mM} \mathrm{GSSG}$. After $20 \mathrm{~h}$ the reaction was checked by HPLC showing that the major component was the folded Kalata B1 (Fig. 1E). The recombinant folded cyclotide was obtained with a yield close to $20 \%$ (based on linear KC4-intein precursor). Using this approach we also produced a small library based on the Kalata B1 scaffold (Fig. 1F).

In summary we report here the first biosynthesis of the cyclotide Kalata B1 in $E$. coli. We have also shown that our biosynthetic approach can be used to generate cyclotide-based libraries that could be screened in vitro or in vivo. Future work will focus in the biosynthesis of cyclotide-based libraries in vivo.
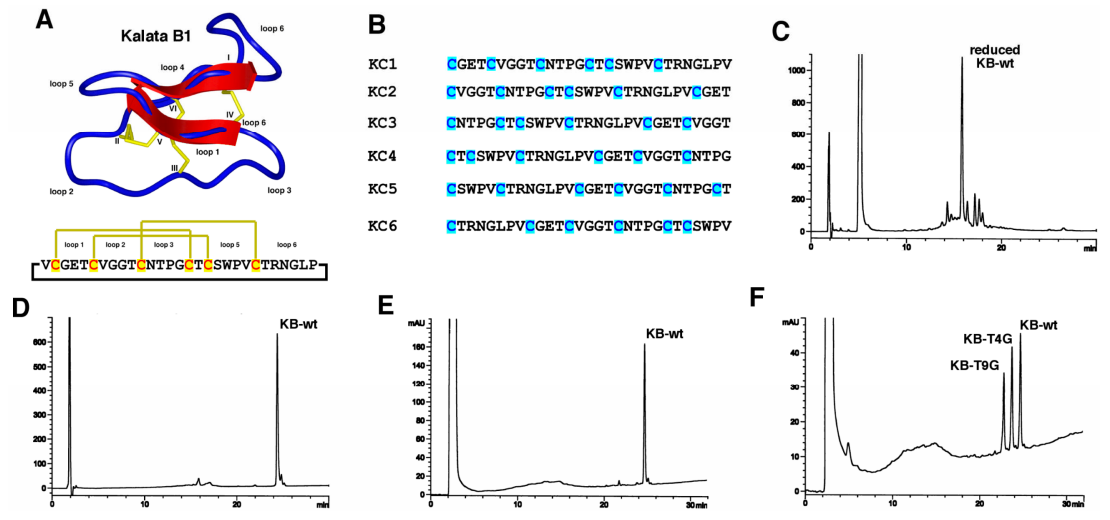

E

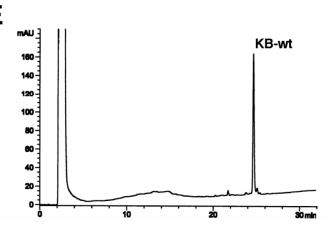

$\mathbf{F}$

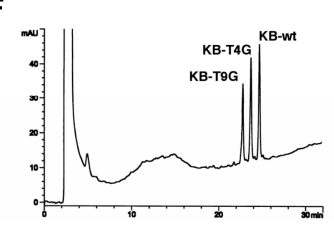

Fig. 1. A. Structure of Kalata B1. B. Sequences of the different linear precursors used in this study (KCl through KC6). C. HPLC trace of the thiolytic cleavage with EtSH of linear precursor KC4-intein construct. D. HPLC trace of the oxidative refolding of reduced Kalata B1. E. HPLC trace of the cyclization and folding accomplished with GSH and GSSG in 50\% ${ }^{i} \mathrm{Pr}-\mathrm{OH}$. F. HPLC trace of the cyclization and folding accomplished as above for a 3 member set of Kalata-based peptides.

\section{Acknowledgments}

This work was performed under the auspices of the U.S. Department of Energy by University of California, Lawrence Livermore National Laboratory under Contract W-7405-Eng-48. We thank Dr. David Craik, University of Queensland, Australia, for kindly providing a sample of natural Kalata B1.

\section{References}

1. Daly, N. L., Love, S., Alewood, P. F. and Craik, D. J. Biochemistry 38, 10606-14 (1999).

2. Craik, D. J., Simonsen, S. and Daly, N. L. Curr. Opin. Drug Discov. Devel. 5, 251-60 (2002).

3. Camarero, J. A. and Muir, T. W. J. Am. Chem. Soc. 121, 5597-8 (1999). 
